\title{
Factors affecting waterfowl hunting and harvest at the Evros delta, Greece
}

\author{
Savas Kazantzidis ${ }^{1, *}$, Christos Astaras ${ }^{1}$, Ioakim Vasiliadis ${ }^{1}$, \\ Eleni Makrygianni ${ }^{2}$, Vassilis Ilias $^{2}$ \& Gavriil Spyroglou ${ }^{1}$ \\ ${ }^{1}$ Forest Research Institute, Hellenic Agricultural Organization "DEMETER", \\ GR-57006, Vassilika, Greece. \\ ${ }^{2}$ Management Body of Evros delta and Samothraki Protected Areas, \\ Evros delta Visitor Center, GR-68100 Traianoupolis, Greece. \\ *Corresponding author: savkaz@fri.gr
}

\begin{abstract}
The Evros delta is one of the most important wetlands for wintering waterfowl in Greece and the most popular among waterfowl hunters. This study addresses hunting activity and harvest while also investigating the relationship between weather conditions and hunting activity to suggest ways of improving waterfowl management. We counted wintering waterfowl and hunter numbers, and conducted hunter bag surveys during December-February over four hunting seasons. We calculated a 10-day goose and duck Preferential Shooting Index (PSI), which is the ratio of observed number of shot birds to the number of birds expected to have been shot if the birds were shot in proportion to their availability. Common Teal, Mallard and Greater White-fronted Goose were the most abundant species both in the field and in hunter bags. The mean number of hunters/day was 99.9, with each one shooting on average $2.5 \mathrm{birds} /$ day. The overall waterfowl harvested accounted for $1.3 \%$ of the total waterfowl population. For geese this proportion was six times higher $(8.7 \%)$, while for ducks alone and protected species was $1.2 \%$ and $1.4 \%$ respectively. Geese were shot more often than expected (PSI 6.55), while ducks and protected species were shot according to their availability (PSI 0.86 and 1.02, respectively). Wind speed, precipitation and geese number in the field were the best predictors of overall harvest and number of hunters. To reduce goose overshooting and the probability of protected species being accidentally shot, we suggest habitat management actions for the geese feeding areas and hunters' awareness raising.
\end{abstract}

Keywords. Ducks, geese, wintering waterbirds, wetland management.

Kazantzidis S., Astaras C., Vasiliadis I., Makrygianni E., Ilias V. \& Spyroglou G. (2020). Factors affecting waterfowl hunting and harvest at the Evros delta, Greece. Belgian Journal of Zoology 150: 135-152.

https://doi.org/10.26496/bjz.2020.77

\section{Introduction}

Hunting is a popular activity in many parts of Greece and is mostly practiced for recreation. At least 160000 hunting licenses were issued annually in the last decade (about $2.7 \%$ of the Greek adult population, HELLENIC STATISTICAL AUTHORITY 2019), which are approximately half of those issued 20 or more years ago (KARAKOSTA 2014; LIORDOS 2014a). The main reason for the reduction 
is thought to be the economic crisis that has curtailed many aspects of everyday life, including outdoor activities. Most Greek hunters prefer hunting birds (thrushes, Woodcock etc.) and mammals (primarily hare and wild boar) in mountainous areas, while approximately 5\% hunt waterfowl (KARAKOSTA 2014). Waterfowl hunting is allowed in certain large wetlands of northern and western Greece. Despite the interest in waterfowl hunting, information related to this form of hunting, such as harvest data, factors that influence hunting intensity, and the impact of hunting on waterfowl populations, have rarely been studied.

Hunting adheres to national rules and regulations that may vary across countries (ELMBERG et al. 2006). In Greece, the waterfowl hunting season extends from 15 September to 10 February (149 days) and involves 10 species. However, only three of them can be hunted after January. Additionally, there are restrictions such as a limit on hunting times (i.e., from half an hour before sunrise to half an hour after sunset), a ban on the use of decoys, a limit of a three-cartridge capacity in guns, etc. Additionally, the daily bag limit for waterfowl is a total of 12 birds per hunter. Incidents of illegal hunting and trapping are often recorded; e.g., day hunting times are rarely respected, bag limits are exceeded, decoys are used occasionally etc. (KAZANTZIDIS et al. 2017). Moreover, illegal killing or trapping of birds is considered a serious threat for many species, including certain waterfowl, across the Mediterranean (BROCHET et al. 2016; DiMITRIOU et al. 2017; KAZANTZIDIS et al. 2017).

Many of the hunting restrictions and management decisions for game species, such as bag limits or duration of the hunting season, are based on insufficient data and untested assumptions - an issue that is true for many European countries (HIRSCHFELD \& HEYD 2005; ELMBERG et al. 2006). For example, hunting quota in Greece are not based on waterfowl harvest data or hunting bag statistics since they are limited, outdated or altogether missing. Information on harvest and hunting bag comes primarily from studies in certain European countries, Australia and the USA (LOYN 1991; HIRSCHFELD \& HEYD 2005; BREgnBalle et al. 2006; PADDING et al. 2006; FoUQUe et al. 2009; HAUGEN et al. 2014; GuILLEMAIN et al. 2016). In the absence of accurate regional information on hunting pressure and factors influencing it, as well as non-hunting mortality, regulations alone are unlikely to achieve sustainable hunting (GEIS et al. 1969; SMITH et al. 1989; BREGNBALLE et al. 2006; PADDING et al. 2006). An obstacle to obtaining accurate information on waterfowl hunting pressure is the complexity of the factors influencing the harvest rates as well as the lack of baseline data for Greece on which to build (SoKOS et al. 2013).

The Evros delta is an important wetland for wintering waterfowl in the Eastern Mediterranean and Black Sea region and the second most important for Greece after Amvrakikos Gulf (DELANY et al. 1999; GILISSEN et al. 2002; HANDRINOS et al. 2015). It hosts big concentrations of species such as Common Teal Anas crecca (over 100000 birds in 1999) and Pintail Anas acuta (GILISSEN et al. 2002; HANDRINOS et al. 2015). Additionally, at least eight more species overwinter in numbers exceeding $1 \%$ of their regional population (HANDRINOS et al. 2015). Among these is the critically endangered Fennoscandian population of the Lesser White-fronted Goose Anser erythropus which winters in its entirety for a few weeks each year at the Evros delta (VougioukAlou et al. 2017) and the Bewick's Swan Cygnus bewickii (VANGELUwe et al. 2018). At the same time, the Evros delta is the most famous and popular wetland for waterfowl hunting among Greek hunters (KAZANTZIDIS et al. 2017).

National Park managers are facing complex problems and challenges, including the need to conserve biological diversity and to protect rare species, that require acquisition of information and knowledge. Additionally, determining what is wise and sustainable exploitative use of waterfowl requires, at a minimum, annual assessment of harvest and harvestable total population size (HOLOPAINEN et al. 2018a).

The aim of this research is to investigate: a) the factors (weather conditions, period and number of birds) that influence hunting activity and waterfowl harvest rates at the Evros delta, and b) the impact of hunting on wintering waterfowl numbers, so as to contribute towards a more evidence-based management 
approach of waterfowl populations in the broader region. Specifically, we: a) provide estimates of the number of waterfowl harvested and of the percentage of the wintering waterfowl numbers that this represents per survey period, b) examine the factors that affect the harvest of geese and ducks, and c) suggest ways of improving wintering waterfowl management.

\section{Material and methods}

\section{Study area}

The Evros delta $\left(40^{\circ} 45^{\prime} 13^{\prime \prime} \mathrm{N}, 26^{\circ} 03^{\prime} 52^{\prime \prime} \mathrm{E}\right)$ straddles the international boundary of Greece and Turkey in the northeast, with the largest part of it belonging to Greece. The Greek section extends over $110 \mathrm{~km}^{2}$ (Fig. 1) and is classified as a Ramsar wetland, a Special Protection Area (SPA), an Important Bird Area (IBA) and a National Park (HANDRINOS et al. 2015). Our study area included the coastal area, three lagoons, saltmarshes and temporary freshwater marshes (ZALIDIS \& MANTZAVELAS 1994). Hunting is permitted in approximately $70 \%$ of the National Park (Fig. 1).

\section{Counts}

We collected data on the wintering waterfowl population, the number of hunters, and waterfowl harvest at the Evros delta over four hunting seasons (2004-2005, 2005-2006, 2012-2013, 2013-2014). The data refer to the counts carried out on the Greek part of the delta where, on average, $81.9 \%$ of the waterbirds of the entire delta are distributed (IOANNIDIS et al. 2015).

The number of wintering waterfowl (23 species of the family Anatidae and Coot Fulica atra) was counted one to three times per month during December, January and February of each hunting season (2004-2005: 7 counts, 2005-2006: 7 counts, 2012-2013: 4 counts, 2013-2014: 5 counts). All counts were carried out along the same route and at the same time of the day, using telescopes and binoculars. The great majority of the Evros delta where ducks and geese occur, based on prior knowledge, was covered during these counts. A small number of unidentified individuals of Anatinae (Anas spp.) was proportionally distributed among the duck species observed during each count.

Hunters were counted by following the same predetermined route during randomly selected survey dates during December, January and February (2004-2005: 7 counts, 2005-2006: 7 counts, 2012-2013: 8counts, 2013-2014: 9 counts). The route was designed to cover the largest possible area in the time
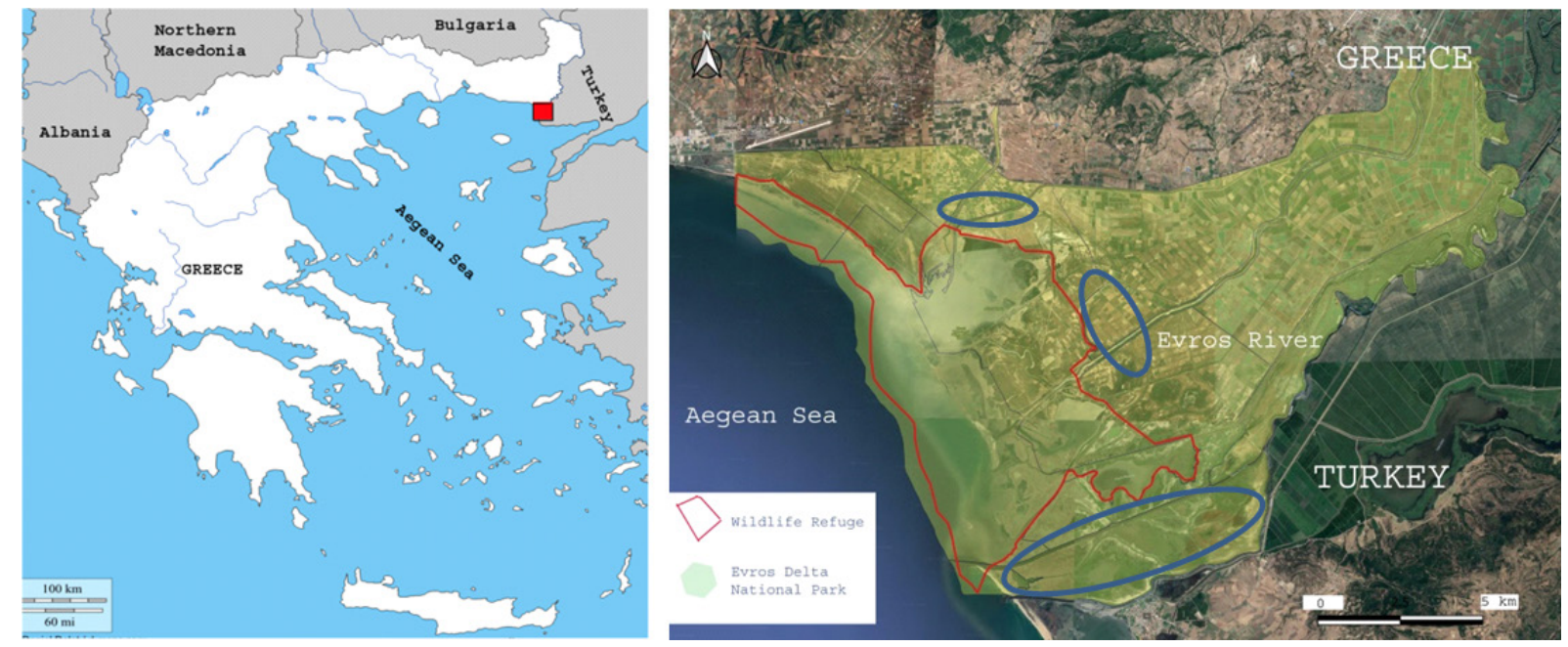

Fig. 1 - Map of the Evros delta (study area). Blue circles indicate the main waterfowl hunting sites. 
available. Hunters were counted directly, but also by adding those detected by gunshots, and those for which their parked cars could be seen (using a mean of two hunters/car - based on field observations).

Hunter bag checks were randomly conducted in collaboration with Forest Service personnel one to four time per month during December, January and February of each hunting season (2004-2005: 6 checks, 2005-2006: 11 checks, 2012-2013: 6 checks, 2013-2014: 10 checks). The checks took place after the completion of morning hunting activity. Hunters were asked to present all bagged birds, which were identified, and to report on which date they were shot (since some hunters took multi-day hunting trips).

\section{Data analysis}

We calculated the total number of birds shot during each hunting season based on the mean number of hunters/day and the mean number of shot birds/hunter/day as estimated from the bag checks.

The analysis was done at the level of the group "geese" (species of the genera Anser and Branta) and the group "ducks" (species of the genus Anas). Species of the genus Aythya (Pochard Aythya ferina, Tufted Duck A. fuligula and Ferruginous Duck A. nyroca) and Coot winter in small numbers at the Evros delta and they are rarely shot. They were for this reason excluded from the analysis. The grouping of duck species for the purpose of the analysis was done because hunters rarely distinguish species before shooting, especially since shooting often takes place after sunset when species identification is almost impossible (KAZANTZIDIS et al. 2017). With regard to geese, they forage and roost in certain sites within the protected area of the Evros delta, where hunting is not allowed. However, every morning a large proportion of them leaves the roosting site to move to other feeding grounds, returning again in the afternoon. It is during this daily movement that they are shot as they fly over the hunting areas. Goose species identification before shooting is also difficult for hunters (DEMERTZI et al. 2017; KAZANTZIDIS et al. 2017), which is why they were also grouped together for the purposes of the analysis. Protected waterfowl species were also grouped for the same reasons (hereafter "protected species").

Weather data (air temperature, precipitation, wind speed) were taken from the nearest meteorological station (Alexandroupolis airport), which is located $<5 \mathrm{~km}$ from the study area.

We summarized our data on waterfowl and hunter numbers, harvest levels and weather at 10-day periods as it was deemed to be the best time scale at which to capture the variation in our different datasets. Additionally, we calculated the Preferential Shooting Index (PSI) for each 10-day period. PSI is the ratio between the observed number of shot birds of a particular species or group of species and the number of birds expected to have been shot if the birds were shot in proportion to their availability, i.e., (number of live birds of the species/number of all waterfowl counted)*total number of waterfowl shot. In effect, PSI is an index, whereby species with a high score are those shot in greater numbers than if shooting was random. A PSI value of 1 indicates that a species/group is hunted in proportion to its availability, while values $<1$ and $>1$ indicate avoidance and preference by the hunters respectively.

We used linear regression (stepwise analysis) to examine relationships among the number of waterfowl recorded in the study area, the number of hunters, time (month and/or year), weather and "geese", "ducks" and "protected species" PSI. Of the 28 10-day periods, we excluded from our analyses those for which bag counts were too few and therefore it was deemed not possible to get reliable estimates of overall harvest rates (and therefore PSI values) or - in the case of geese - the total proportion of geese of all waterfowl was lower than 5\%, as in this case PSI values were very sensitive to even minor biases in the number of geese observed in bag counts. Further outlying values were also excluded from the analysis. All analysis was undertaken using SPSS (ver. 21). Statistical significance was defined at 0.05. 


\section{Results}

\section{Wintering waterfowl populations}

The mean wintering waterfowl number at the Evros delta for a 10-day period across the four hunting seasons was $70956 \pm 49426$ (SD) ( $n=23$ counts; 24 species included, Appendix 1). There was no significant difference among the years $\left(\mathrm{F}_{(3,23)}=1.865, \mathrm{p}=0.164\right)$. Within each season the highest waterfowl population was recorded in January at three occasions and in December in 2013-2014.

Common Teal, Mallard Anas platyrhynchos and Eurasian Wigeon Mareca penelope were the most abundant species, accounting together for 78\% (2005-2006) to 92\% (2013-2014) of all waterfowl recorded in each season. That proportion for the ten most hunted species was $96-98 \%$ across seasons (Appendix 1).

Geese amounted on average to $1.9 \%$ of all wintering waterfowl at the Evros delta. Most were Greater White-fronted Goose Anser albifrons (94.9\%) and the rest Greylag Goose Anser anser (2.7\%), Lesser White-fronted Goose Anser erythropus (1.9\%) and Red-breasted Goose Branta ruficollis (0.5\%).

The factors best predicting the total geese population at the Evros delta were air temperature (negative relationship) and month (February having the largest number of geese present $)\left(F_{(1,24)}=13.653, p=0.001\right.$, Table 1).

The lowest temperatures at the Evros delta were recorded in late January-early February and the mean daily low temperature during the 10 -day periods ranged from $-0.68^{\circ} \mathrm{C}$ to $0.28^{\circ} \mathrm{C}$. Nevertheless, no significant correlations were recorded among monthly air temperature $\left(\mathrm{F}_{(2,21)}=0.31, \mathrm{p}=0.970\right)$, precipitation $\left(\mathrm{F}_{(2,21)}=1.491, \mathrm{p}=0.248\right)$, and wind speed $\left(\mathrm{F}_{(2,21)}=0.229, \mathrm{p}=0.797\right)$.

Of the 24 waterfowl species observed in the study area, nine are included in the Red Data Book of threatened animals of Greece (LEGAKIS \& MARAGOU 2009). Additionally, seven are included in Annex I of the Bird Directive, of which one is a hunted species. Four species are not included either in the above-mentioned lists or the list of hunted species: Goldeneye Bucephala clangula, Mute Swan Cygnus olor, Red-breasted Pochard Netta rufina, and Red-breasted Merganser Mergus serrator (Appendix 1). The non-hunted species accounted from $2.2 \%$ in 2013-2014 (2576 \pm 1419 birds) to $4.4 \%$ in 2005-2006 (3132 \pm 4158 birds) of all waterfowl recorded (Appendix 1).

\section{Number of hunters}

The mean number of hunters/day varied significantly among the hunting seasons $\left(99.9 \pm 95.7, \mathrm{~F}_{(34,3)}=\right.$ $6.021, \mathrm{p}=0.002)$. The highest number $(213 \pm 167$ hunters/day, $n=7)$ was recorded in 2004-2005, which was 2-3 times higher than the mean values reported for other seasons $(2005-2006: 88 \pm 37, \mathrm{n}=8 ; 2012-$ 2013: $65 \pm 37, \mathrm{n}=11 ; 2013-2014: 65 \pm 26, \mathrm{n}=9$ ). There was no significant variation in the number of hunters across months $\left(\mathrm{F}_{(34,2)}=1.722, \mathrm{p}=0.19, \mathrm{n}=35\right)$.

\section{TABLE 1}

Factors influencing the number of geese wintering during four hunting seasons (2004-2005, 2005-2006, 2012-2013 and 2013-2014) at the Evros delta.

\begin{tabular}{lcccc}
\hline Model & B & SE & t-value (p) & Adj. $\mathbf{R}^{2}$ \\
\hline Intercept & 3103234 & 337298 & & \\
Month & -129223 & 28745 & $-4.495(0.000)$ & \\
Temperature (mean $\left.{ }^{\circ} \mathrm{C}\right)$ & -188436 & 50998 & $-3.695(0.001)$ & 0.613 \\
\hline
\end{tabular}




\section{Harvest}

In total, 319 hunters were checked (on average $6.6 \%$ of the recorded hunters during the survey day) and 1102 shot waterfowl were found in their bags. Of the 16 species identified, 10 were quarry species (including one Anas platyrhynchos X Anas acuta hybrid individual) and six were protected species. We also recorded individuals of two waders (Redshank Tringa totanus (Linnaeus, 1758) and Snipe Gallinago gallinago (Linnaeus, 1758)) and two passerines (Starling Sturnus vulgaris Linnaeus, 1758 and Song Thrush Turdus philomelos C.L. Brehm, 1831) that were not included in the analysis.

The most frequently shot species was Common Teal followed by Mallard and Greater White-fronted Goose (Fig. 2).

Among the protected species, the most frequently bagged was Shelduck Tadorna tadorna that was recorded in several bags in two hunting seasons. Greylag, Red-breasted Goose, Ferruginous Duck, Smew Mergellus albellus and Goldeneye were recorded only once or twice.

The harvest (mean number of shot birds/hunter/day) was 2.5 birds and did not differ among the hunting seasons $\left(\mathrm{F}_{(3,24)}=2.502, \mathrm{p}=0.076\right)$. However, differences were recorded among months $\left(\mathrm{F}_{(2,1)}=4.255\right.$, $\mathrm{p}=0.022)$. The highest harvest was recorded in February $(5.6 \pm 7.5$ birds/hunter/day, $\mathrm{n}=12)$ followed by January $1.2 \pm 1.9(\mathrm{n}=16)$ and December $(0.97 \pm 0.6, \mathrm{n}=10)$.

The estimated mean number of waterfowl harvested each 10-day period was $1.3 \%$ of the total waterfowl population recorded on the Greek side of the Evros delta during that period. However, there were differences among waterfowl type and the hunting seasons. The mean number of geese shot was $8.7 \%$ of the total geese population, while for the ducks it was $1.2 \%$. Regarding protected species, $1.4 \%$ of their observed population was shot.

The average PSI for geese was 6.55 , indicating that they were shot more often than expected from their proportion of the total waterfowl population. Although they were rarely shot during the first hunting season (2004-2005) of the research period (very high PSI was recorded only once), geese were a preferred quarry during the last two hunting seasons (Fig. 3). On the other hand, ducks were shot nearly

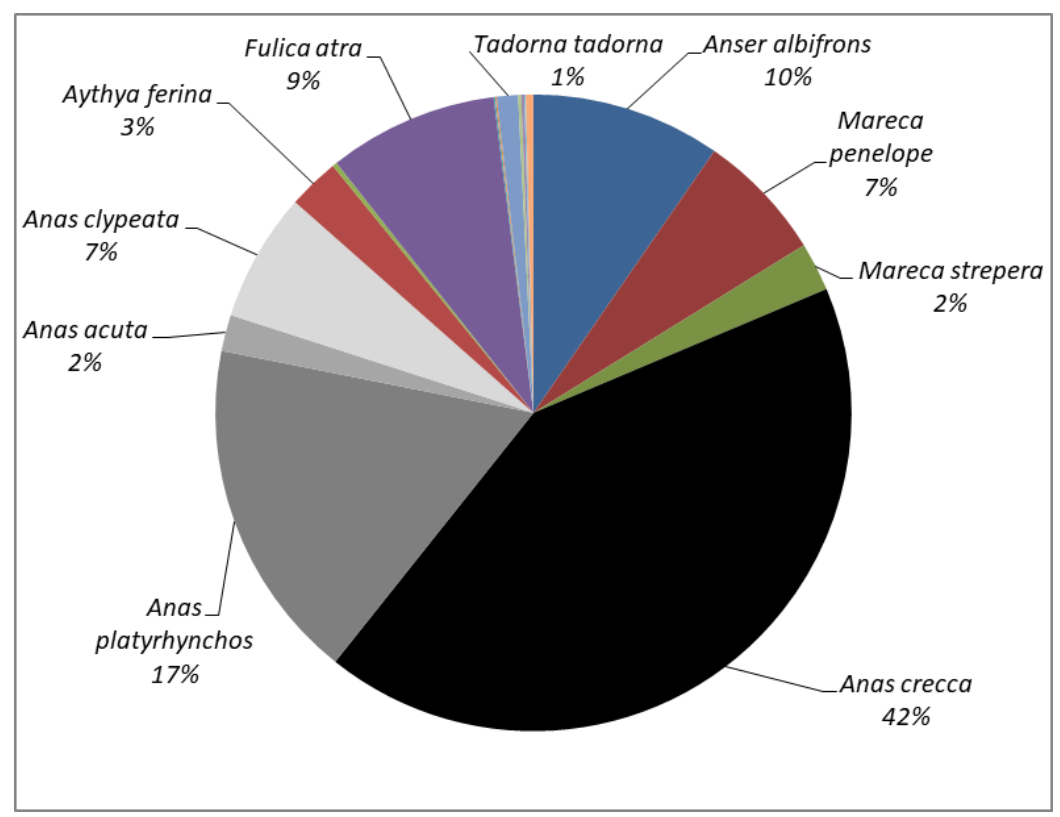

Fig. 2 - Percentage of shot waterfowl species recorded at hunters' bag during four hunting seasons at the Evros delta. 
TABLE 2

Factors influencing harvest during four hunting seasons (2004-2005, 2005-2006, 2012-2013 and 20132014) at the Evros delta.

\begin{tabular}{lcccc}
\hline Model & B & SE & t-value (p) & Adj. $\mathbf{R}^{2}$ \\
\hline Intercept & -274759 & 408840 & & \\
Wind & 109653 & 33719 & $3.252(0.004)$ & 0.294 \\
\hline
\end{tabular}

in proportion to their availability (average PSI $=0.86$ ranging $0.16-1.18$, Fig. 3 ). The protected species were shot according to their availability in the field (average PSI $=1.02$ ).

\section{Harvest predictors}

The overall number of waterfowl shot during a 10-day period was positively related to wind speed $\left(\mathrm{F}_{(1,22)}=10.576, \mathrm{p}=0.004\right.$, Table 2$)$.

In addition, the number of shot geese alone depended on the number of geese in the field (the higher the number of geese, the higher the harvest, $\mathrm{F}_{(1,22)}=10.499, \mathrm{p}=0.004$, Table 3). In terms of the PSI for geese, it was positively related to the number of geese in the field and negatively related to wind speed $\left(\mathrm{F}_{(1,21)}=7.736, \mathrm{p}=0.003\right.$, Table 4).

Common Teal and Mallard accounted for the majority of individuals of the genus Anas, both in field and bag counts. The highest number of ducks shot was recorded in February $\left(\mathrm{F}_{(2,23)}=8.027, \mathrm{p}=0.002\right)$. Unlike with geese, wind speed was positively related to the number of ducks shot $\left(\mathrm{F}_{(1,22)}=23.359\right.$, $\mathrm{p}=0.000$, Table 5). The PSI of ducks was negatively related to precipitation $\left(\mathrm{F}_{(1,22)}=5.291, \mathrm{p}=0.031\right.$, Table 6).

\section{Hunter numbers}

We identified two factors that are positively related to the number of hunters present in the area: wind speed and the total number of geese in the area (Table 7, $\mathrm{F}_{(2.24)}=14.041, \mathrm{p}=0.000$ ).

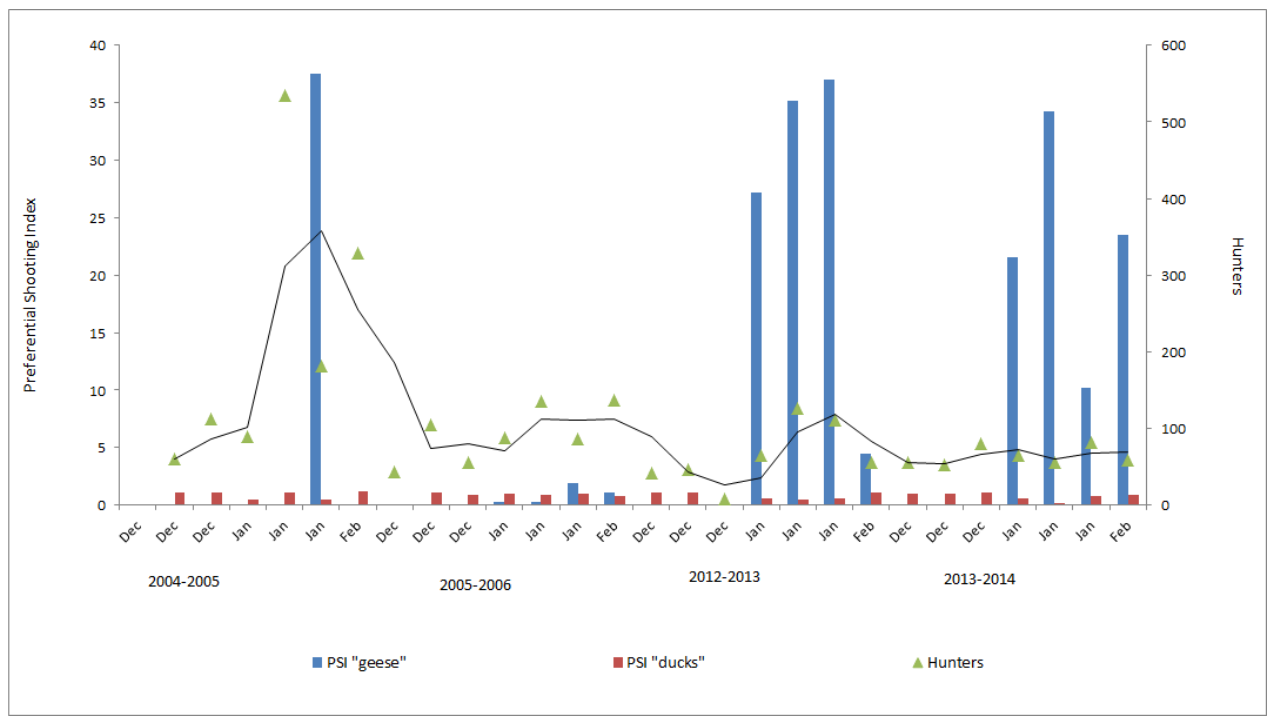

Fig. 3 - Preferential Shooting Index (PSI) for the groups "geese" and "ducks" and number of hunters during four hunting seasons at the Evros delta. 


\section{TABLE 3}

Factors influencing the number of geese shot during four hunting seasons (2004-2005, 2005-2006, 2012-2013 and 2013-2014) at the Evros delta.

\begin{tabular}{lcccc}
\hline Model & B & SE & t-value (p) & Adj. $\mathbf{R}^{2}$ \\
\hline Intercept & -18386 & 56599 & & \\
Geese number in the field & 0.106 & 0.033 & $3.240(0.004)$ & 0.302 \\
\hline
\end{tabular}

TABLE 4

Factors influencing the Preferential Shooting Index of geese shot during four hunting seasons (20042005, 2005-2006, 2012-2013 and 2013-2014) at the Evros delta.

\begin{tabular}{lcccc}
\hline Model & B & SE & t-value (p) & Adj. $\mathbf{R}^{\mathbf{2}}$ \\
\hline Intercept & 19876 & 5258 & & \\
Wind & -1756 & 0.429 & $-3.669(0.001)$ & \\
Geese number in the field & 0.004 & 0.002 & $2.207(0.039)$ & 0.369 \\
\hline
\end{tabular}

TABLE 5

Factors influencing the number of ducks shot during four hunting seasons (2004-2005, 2005-2006, 2012-2013 and 2013-2014) at the Evros delta.

\begin{tabular}{lcccc}
\hline Model & B & SE & t-value (p) & Adj. $\mathbf{R}^{2}$ \\
\hline Intercept & -390332 & 255784 & & \\
Wind & 101956 & 21096 & $4.833(0.000)$ & 0.493 \\
\hline
\end{tabular}

\section{Discussion}

\section{Wintering waterfowl populations}

The Evros River delta is home to $25.9 \%$ of the total wintering waterfowl population of Greece, second only to Amvrakikos Gulf, and has the richest diversity of wintering waterfowl species - including protected species - among all Greek wetlands (PORTOLOU et al. 2009; HANDRINOS et al. 2015). It is also especially important for geese, as more than half of Greece's geese wintering population were at the Evros delta from 1997 to 2006 . The wintering waterfowl numbers have fluctuated widely with no apparent trend during the period 1968-2006 (HANDRINOS et al. 2015). Common Teal and Mallard, were the most abundant wintering species of genus Anas not only at the Evros delta but also at the Eastern Mediterranean-Black Sea zoogeographical area, having increasing (Common Teal) or stable (Mallard) numbers (DELANY et al. 1999; GILISSEN et al. 2002; DELANY \& SCOTT 2006). Overall in Greece, certain hunted species' numbers declined (Wigeon, Pintail, Coot) while some other (Mallard, Common Teal) showed high fluctuations or increased. With regard to geese, the numbers of all species at the Evros delta were increasing during the period 1997-2006 (HANDRINOS et al. 2015) and decreasing during 
TABLE 6

Factors influencing the Preferential Shooting Index of ducks shot during four hunting seasons (20042005, 2005-2006, 2012-2013 and 2013-2014) at the Evros delta.

\begin{tabular}{lcccc}
\hline Model & B & SE & t-value (p) & Adj. $\mathbf{R}^{2}$ \\
\hline Intercept & 1016 & 0.102 & & \\
Precipitation $(\mathrm{mm})$ & -0.003 & 0.001 & $-2.300(0.031)$ & 0.157 \\
\hline
\end{tabular}

\section{TABLE 7}

Factors influencing the number of hunters during four hunting seasons (2004-2005, 2005-2006, 20122013 and 2013-2014) at the Evros delta.

\begin{tabular}{lcccc}
\hline Model & B & SE & t-value (p) & Adj. $\mathbf{R}^{2}$ \\
\hline Intercept & 8827 & 19297 & & \\
Wind & 4761 & 1604 & $2.968(0.007)$ & \\
Geese number in the field & 0.022 & 0.007 & $3.793(0.001)$ & 0.521 \\
\hline
\end{tabular}

2012-2014 (present research). Overall, the population of Greater White-fronted and Greylag Goose in the Pontic/Anatolian area seem to have declined during the period 1986-2012 (FOX \& LEAFLOOR 2018).

The wintering waterfowl numbers were the highest during January and February; however, the highest numbers of geese were recorded later, in February or even March (HANDRINOS \& AKRIOTIS 1997).

\section{Number of hunters}

The Evros delta is by far the most popular wetland among Greek waterfowl hunters and attracts hunters from across the country (KAZANTZIDIS et al. 2017). The main reason is that the easternmost part of the National Park (a remote area where access is possible by boat only), where there is high waterfowl abundance and diversity, is almost exclusively dedicated to hunting and no other human activity takes place during the hunting season. Additionally, the ability to stay overnight at the hunting huts close to the hunting zones (although not allowed) and the number of birds flying over or foraging at the extensive and shallow marshes, offer unique hunting conditions. Since the bag size of hunters did not change during our study, the observed decrease in the number of hunters in the last two hunting seasons is likely due to the economic crisis and recession in Greece. From 2008 to 2016, the gross domestic product per capita has dropped by approximately 25\% (LIORDOS 2014b; MAVRIDIS 2018) and it is logical to expect this has affected the disposable income available for recreational activities such as hunting. The financial crisis seems to have affected hunter numbers at the Evros delta particularly, since many hunters came from other parts of Greece and must pay higher travel and accommodation costs than local hunters. A decline of hunter numbers has been recorded elsewhere in Europe, such as in Denmark and France (Christensen 2005; Guillemain et al. 2016). Specifically, at the Camargue the number of hunters was reduced by approximately 22\% from 1999 to 2008 (MONDAIN-MONVAL et al. 2006) while overall in France, hunter numbers dropped by a million to 1.2 in four decades (1974-2014, GUILLEMAIN et al. 2016). 


\section{Harvest}

The harvested species we recorded at the Evros delta are similar to those recorded in other European, Asian and North American wetlands (HARRAdine 1985; MondAIn-Monval \& GiRARD 2000; MoOIJ 2005; BaldassarRe \& Bolen 2006; BALMAKi \& BARATI 2006; Mondain-Monval et al. 2006; SORRENTI et al. 2006; GUILLEMAIN et al. 2016).

The daily harvest per hunter can vary within and across sites for a multitude of reasons, such as differences in target species, waterfowl population variations across seasons and years, the hunters' experience, morphology of the area or guns used. Therefore, meaningful comparisons among sites and countries are difficult to be made. In addition, differences in the data collection (e.g., some countries rely on hunter questionnaires) or reporting methods (e.g., harvest per hunter per season, total harvest per flyway) further complicate comparisons (CONNELLY et al. 2005; STAFFORD et al. 2010). According to LOGOTHETIS (1998), harvest/hunter/day from the Evros delta was 1.9 birds in 1997-98. In Illinois (USA) the mean number of mallards/hunter/day in 1981-2002 was $0.5 \pm 0.3$ and for all dabbling ducks $0.7 \pm 0.3$ (STAFFORD et al. 2010). Therefore, the value reported in this study ( 2.5 birds/hunter/day) is among the highest on record. However, it should be noted that it reflects harvest for December to 10 February and not the entire hunting season. Hunting activity is scarce in September and October, and very low in November typically (KAZANTZIDIS et al. 2017). It is possible that the overall season mean is therefore lower. The fact that we observed the highest harvest rates in February is in accordance to what has been reported before. The overall waterfowl population in the wetland is higher - including birds that are migrating through the area, so there is more game available. Moreover, birds that overwintered in the area start their migration to their breeding grounds and so they are continuously moving, which makes them more vulnerable to hunting (GUILLEMAIN et al. 2016).

\section{Hunting impact}

The Greater White-fronted goose is a popular quarry in Greece, but is thought to be intolerant of high hunting pressure (SOKOS et al. 2013). In our study area, most of the wintering geese concentrate within the protected areas to roost for the night. Many of them perform daily flights northwards-northeastwards to the feeding grounds. After take-off, they overfly certain nearby hunting grounds where goose hunters are concentrated since they know the geese's daily movement pattern. The easily accessible hunting grounds (i.e., no boat needed) close to the geese roosting areas so as for the birds to be within shooting range soon after take-off and before gaining altitude, probably explains the relatively high numbers of geese shot. Although the population of the Greater White-fronted Goose in Europe has increased, the population in Greece, Turkey and the Black Sea has probably declined to 240,000-250,000 individuals (NAGY et al. 2014; FOX \& LEAFLOOR 2018). Even if the overall number of shot geese at the Evros delta is just a small percentage of the European population $(<0.5 \%)$, there is concern about the high risk of shooting the three protected geese species that form mixed flocks with the Greater White-fronted Geese. In fact, there are many incidents of illegally shooting protected waterfowl species in Greece including a Lesser White-fronted goose (TsOUGRAKIS et al. 2009; DEMERTZI et al. 2017).

Most of the duck species are considered popular targets for Greek hunters (SOKOS et al. 2013). Ducks search for foraging sites during the early morning hours and during late afternoon or even during the night. Unlike geese however, they do not all concentrate on the same foraging areas, and therefore their flyways are less predictable. We believe that this explains why ducks are harvested more or less in proportion to their availability in the wetland.

What is worrisome, however, is that there is no evidence in our records that protected species are less likely to be shot than random, i.e., the hunters are either unable or unwilling to avoid shooting them. We believe that the timing of most hunting activity (i.e., dusk and dawn - when light conditions are poor) makes species identification practically impossible. According to KAZANTZIDIS et al. (2017), 
more than one third of the shots occurs from half an hour after sunset (the legal end of the hunting day) and up to three hours later. Such violations of hunting regulations occur due to lack of awareness of hunting regulations among some hunters, while enforcement of hunting regulations and controls by the responsible authorities is limited. For instance, one in five hunters surveyed at the Evros delta does not know that the Lesser White-fronted Goose, the rarest waterbird in the EU that winters at the Evros delta, is a strictly protected species (KAZANTZIDIS et al. 2017). Overall, the occurrence of illegal hunting is not unique to the study area, as it is occurs in many parts of Greece and in other Mediterranean countries as well, and many protected species are shot primarily during the legal hunting period (MAZARIS et al. 2008; BROCHET et al. 2017; BALMORI 2019).

\section{Hunting activity drivers}

There are many factors that can affect the harvest, e.g., reproductive output, breeding population size, temperature (STAFFORD et al. 2010; SOKOS et al. 2013; HOLOPAINEN et al. 2018b). Weather conditions and especially wind has previously been reported to affect waterfowl harvest (JOHNSON \& VRTISKA 2014), as we report here. It is perhaps surprising, however, that wind speed and temperature are even better predictors of waterfowl harvest rates than overall waterfowl population in the wetland. Strong winds can make it difficult for some duck species to feed, affecting their time budgets (BALDASSARRE \& BOLEN 2006). Such stressful conditions force ducks more often into searching for feeding sites that are more protected from the weather, exposing them more often to hunters. Similarly to what we observed in the Evros delta, Common Teal harvest was also positively affected by wind speed (and cold spells) in Camargue, France (GALIA et al. 2017). On the contrary, the goose harvest at the Evros delta is negatively related to the wind, probably because geese avoid flying altogether in windy conditions, and is positively related to their number in the field.

The fact that during windy days there were more hunters in our study area suggests that they recognize the increased vulnerability of ducks in such weather conditions, and are more likely to go hunting in such conditions. Another factor that attracts hunters at the hunting grounds is the number of geese in the wetland, which shows that hunting trips are organized based on feedback from the field rather than occurring randomly or based on the calendar.

\section{Conclusions}

Our results show that weather conditions and bird numbers affect waterfowl harvest and hunting levels in the Evros delta. Since these parameters can vary considerably across and within hunting seasons and cannot be controlled by the site managers, it is difficult to estimate the annual harvest levels without regular data from the field. Bag controls should be continued but also expanded to include additional information, such as the sex and age of bagged birds. We also propose the use of passive acoustic monitoring techniques (ASTARAS et al. 2017) for estimating the hunting pressure at the Evros delta based on actual hunting incidents (i.e., gunshots). The number of gunshots per season, when combined with hunter success rate - which can be obtained from hunter interviews -, the species' proportion of harvested animals calculated from the bag counts, and the waterfowl survey data, could allow an accurate estimate of annual waterfowl harvest. Such insight on the potential sustainability of current hunting pressure would allow the adaptation of bag limits based on robust site-specific evidence. In order to reduce the risk of accidentally shooting protected geese species (e.g., Lesser White-fronted, Red-breasted and Greylag Geese) and to curb overshooting geese, we propose management actions that aim to retain more geese within the protected zones of the park by improving foraging opportunities in these areas. Specifically, meadows near the geese roosting sites could be partially flooded during winter and seeded with plants known to be grazed by geese (KARMIRIS et al. 2011, 2017). An awareness raising campaign among hunters regarding protected species (targeting those hunters specializing on geese) would also be very useful. In order to minimize illegal incidents, more anti-poaching patrols should be taken by pertinent authorities and local hunting clubs. 


\section{Acknowledgements}

All the work of the Forest Research Institute is supported financially by the Hellenic Ministry of Rural Development and Food. This particular research was partly funded by the Ministry of Rural Development and Food in the framework of the project "Hunting impact on waterfowl in Greece" (2004-2009), the EU through the LIFE +10NAT/GR/000638 Project "Safeguarding the Lesser White-fronted Goose Fennoscandian population at key staging and wintering sites within the European flyway", and the Norwegian Environmental Agency that partly financially supported the LIFE+ project. We would like to thank Panayiotis Vafeidis and Kostas Vassilakis of the Forest Services of Xanthi and Soufli for their participation in the field work during hunters' bag controls. We also thank the staff of the Management Body of the Evros delta and Samothraki Protected Areas and especially Tasos Anastasiadis, Tasos Nikolaros, Yiannis Fakriadis, Giorgos Voulgaridis, Vangelis Sirkelidis, Andreas Athanasiadis and Kostas Poirazidis for their valuable contribution to the fieldwork. We are indebted to George Handrinos (former head of Game and Wildlife Department of the Hellenic Ministry of Rural Development and Food) and Didier Vangeluwe (Royal Belgian Institute of Natural Sciences), for the long discussions about the waterbirds and the management of the Evros delta. Finally, we would like to thank a reviewer whose comments and suggestions improved the manuscript and all hunters at the Evros delta for their cooperation and information on hunting and harvest.

\section{References}

Astaras C., Linder J.M, Wrege P.H, Orume R.D. \& MAcdonald D.W. (2017). Passive acoustic monitoring as a law enforcement monitoring tool for Afrotropical rainforests. Frontiers in Ecology and the Environment 15: 233-234. https://doi.org/10.1002/fee.1495

BaldassarRe G.A. \& Bolen E.G. (2006). Waterfowl Ecology and Management. Krieger Publishing, Florida.

BALMAKI B. \& BARATI A. (2006). Harvesting status of migratory waterfowl in northern Iran: a case study from Gilan Province. In: Boere G.C., Galbraith C.A. \& Stroud D.A. (eds) Waterbirds around the World: 868-869. The Stationery Office, Edinburgh.

BALMORI A. (2019). Endangered bird mortality by gunshots: still a current problem. Biodiversity and Conservation 28: 2555-2564. https://doi.org/10.1007/s10531-019-01778-9

Bregnballe T., Noer H., Christensen T.K., Clausen P., Asferg T., Fox A.D. \& Delany S. (2006). Sustainable hunting of migratory waterbirds: the Danish approach. In: BOERE G.C., GALBRAITH C.A. \& STROUD D.A. (eds) Waterbirds around the World: 854-860. The Stationery Office, Edinburgh.

Brochet A.L., Van Den Bossche W., Jbour S., Ndang'Ang'a P.K., Jones V.R., Wal I.A., AlHmoud A.R., Asswad N.G., Atienza J.C., Atrash I., Barbara N., Bensusan K., Bino T., Celada C., Cherkaoui S.I., Costa J., Deceuninck B., Etayeb K.S., Feltrup-Azafzaf C., Figelj J., Gustin M., KMecl P., Kocevski V., Korbeti M., Kotrošan D., Laguna J.M., LatTuada M., Leitão D., Lopes P., LóPez-Jiménez N., Lucić V., Micol T., MoAli A., Perlman Y., Piludu N., Portolou D., Putilin K., Quaintenne G., Ramadan-Jaradi G., Ružić M., SANdor A., Sarajli N., Saveljić D., Sheldon R.D., Shialis T., Tsiopelas N., Vargas F., Thompson C., BRUNNER A., GrimMETt R. \& BUtCHART S.H.M. (2016). Preliminary assessment of the scope and scale of illegal killing and taking of birds in the Mediterranean. Bird Conservation International 26: 1-28. https://doi.org/10.1017/S0959270915000416

Christensen T.K. (2005). Factors affecting the bag size of the common eider Somateria mollissima in Denmark, 1980-2000. Wildlife Biology 11: 89-99.

https://doi.org/10.2981/0909-6396(2005)11[89:FATBSO]2.0.CO;2 
Connelly W.J., Gammonley J.H. \& PeeK J.M. (2005). Harvest management. In: Braun C.E. (ed.) Techniques for Wildlife Investigation and Management. $6^{\text {th }}$ Edition: 658-690. The Wildlife Society, Maryland.

DELANY S. \& SCOTT D. (2006). Waterbird Population Estimates - Fourth Edition. Wetlands International, Wageningen.

Delany S., Reyes C., Hubert E., Pihl S., Rees E., HaAnstra L. \& Van Strien A. (1999). Results from the International Waterbird Census in the Western Palearctic and Southwest Asia 1995 and 1996. Wetlands International Publication No 54. Wageningen.

Demertzi A., Vougioukalou M. \& VAFEIDis P. (2017). A combined patrolling scheme for safeguarding the Lesser White-fronted Goose in Greece. In: Vougioukalou M., KAZANTZIDIS S. \& AARVAK T. (eds) Safeguarding the Lesser White-fronted Goose Fennoscandian Population at key staging and wintering Sites within the European Flyway: 109-118. HOS/Birdlife Greece, HAOD/Forest Research Institute, NOF/Birdlife Norway, Athens.

Dimitriou C.A., Forcina G., Papazoglou C., Panayides P., Guerrini M., Crabtree A., BARBANERA F. \& SFENDOURAKIS S. (2017). DNA barcoding of bird species in Cyprus: a tool for conservation purposes. Bird Conservation International 27: 483-494.

https://doi.org/10.1017/S0959270916000472

HELLENIC STATISTICALAUTHORITY. (2019). Greece in Figures January-March 2019. Available from http://www.statistics.gr/en/greece-in-figures [accessed 15 June 2019].

Elmberg J., Nummi P., Pöysä H., Sjöberg K., Gunnarsson G., Clausen P., Guillemain M., RODRIGUES D. \& VÄÄNÄNEN V.M. (2006). The scientific basis for new and sustainable management of migratory European ducks. Wildlife Biology 12: 121-127.

https://doi.org/10.2981/0909-6396(2006)12[121:TSBFNA]2.0.CO;2

Fouque C., Guillemain M. \& SCHICKE V. (2009). Trends in the numbers of Coot Fulica atra and wildfowl Anatidae wintering in France, and their relationship with hunting activity at wetland sites. Wildfowl 59 (Suppl. 2): 42-59.

Fox A.D. \& LeAfloor J.O. (2018). A Global Audit of the Status and Trends of Arctic and Northern Hemisphere Goose Populations (Component 2: Population accounts). Conservation of Arctic Flora and Fauna International Secretariat. Akureyri. Available from http://www.caff.is/goose [accessed 4 August 2019].

Galia J., Defos Du Rau P., Olivier A., Guillemain M., Nourry C., Langendoen T., Nagy S. \& Mondain-Monval J.Y. (2017). Trends in Teal bag in the Camargue: impact of weather and multiscale abundance. In: BRO E. \& GUILlEMAIN M. (eds) 33rd IUGB Congress and $14^{\text {th }}$ Perdix Symposium abstract book: 134. ONCFS, Paris.

Geis A.D., MARTinson R.K. \& ANDERSON D.R. (1969). Establishing hunting regulations and allowable harvest of mallards in the United States. Journal of Wildlife Management 33: 848-59. https://doi.org/10.2307/3799316

Gilissen N., HaAnstra L., Delany S., Boere G. \& HagemeiJer W. (2002). Numbers and distribution of wintering waterbirds in the Western Palearctic and Southwest Asia in 1997, 1998 and 1999. Results from the International Waterbird Census. Wetlands International Global Series No. 11, Wageningen.

Guillemain M., Aubry P., Folliot B. \& Caizergues A. (2016). Duck hunting bag estimates for the 2013/14 season in France. Wildfowl 66: 126-141.

HANDRINOS G. \& AKRiOTIS T. (1997). The Birds of Greece. C. Helm, London. 
Handrinos G., Kazantzidis S., Alivizatos C., Akriotis T. \& Portolou D. (2015). International Waterbird census in Greece (1968-2006): Analysis of the population of wildfowl (Anseriformes) and the Coot (Fulica atra). Hellenic Ornithological Society - Hellenic Bird Ringing Center, Athens [in Greek with English summary].

HARRADINE J. (1985). Duck shooting in the United Kingdom. Wildfowl 36: 81-94.

Haugen T.M., Powell L.A. \& VRTiska M.P. (2014). Assessment of spatial changes in the duck harvest within the Central Flyway, 1997-2011. Wildfowl 64: 75-90.

HiRSCHFELD A. \& HEYD A. (2005). Mortality of migratory birds caused by hunting in Europe: bag statistics and proposals for the conservation of birds and animal welfare. Berichte zum Vogelschutz 42: $47-74$.

Holopainen S., Arzel C., Elmberg J., Fox A.D., Guillemain M., Gunnarsson G., Nummi P., SJÖBERG K., VÄÄNÄNEN V.-M.,ALHAINEN M. \& PÖYSÄH. (2018a). Sustainable management of migratory European ducks: finding model species. Wildlife Biology 2018 (1). https://doi.org/10.2981/wlb.00336

Holopainen S., Christensen T.K., Poysa H., VaAnanen V.-M., Rintala J. \& Fox A.D. (2018b). Associations between duck harvest, hunting wing ratios and measures of reproductive output in Northern Europe. European Journal of Wildlife Research 64: 72-80. https://doi.org/10.1007/s10344-018-1227-5

IOANNidis P., Mulayim M.O., Makrigianni E., Gezgin C., Athanasiadis A. \& CATSADORAKis G. (2015). The first simultaneous counts in the Greek and Turkish parts of the Evros/Meric delta reveal its true value for wintering waterbirds. In: Poulakakis N., ANTONIOU A., KARAMETA E., Psonis N. \& VARDINOYANNIS K. (eds) Abstracts of the $13^{\text {th }}$ International Congress on the Zoogeography and Ecology of Greece and Adjacent Regions: 45. Hellenic Zoological Society.

JOHNSON M.H. \& VRTISKA M.P. (2014). Weather variables affecting Canada goose harvest in Nebraska. Great Plains Research 24: 135-143. https://doi.org/10.1353/gpr.2014.0027

Karakosta H. (2014). Forest Service Activities Report 2011. Ministry of Environment, Energy and Climate Change, Athens.

Karmiris I., Platis P., Kazantzidis S. \& Papachristou T. (2011). Diet selection by domestic and wild herbivores in a coastal Mediterranean wetland. Annales Zoologici Fennici 48: 233-242. https://doi.org/10.5735/086.048.0404

Karmiris I., Platis P., PAPAChristou T. \& KazAntZidis S. (2017). Grassland management at Evros delta, a wintering habitat for the Lesser White-fronted Goose Anser erythropus in northern Greece. In: Vougioukalou M., KaZANTZIDIS S. \& AARVAK T. (eds) Safeguarding the Lesser White-fronted Goose Fennoscandian Population at key staging and wintering Sites within the European Flyway: 7983. HOS/Birdlife Greece, HAOD/Forest Research Institute, NOF/Birdlife Norway, Athens.

KaZANTZidis S., VASiliadis I., MaKrigianni E., Ilias V., PAPAChristou T., Platis P. \& Karmiris I. (2017). Impact of hunting activities on waterfowl at the Evros delta, Greece. In: VougiOUKALOU M., KAZANTZIDIS S. \& AARVAK T. (eds) Safeguarding the Lesser White-fronted Goose Fennoscandian Population at key staging and wintering Sites within the European Flyway: 94-101. HOS/Birdlife Greece, HAOD/Forest Research Institute, NOF/Birdlife Norway, Athens.

Legakis A. \& Maragou P. (2009). The Red Book of the threatened Animals in Greece. Hellenic Zoological Society, Athens.

LioRdOS V. (2014a). Sociodemographic analysis of hunters' preferences: a Greek Hunting Club perspective. Zoology and Ecology 24 (4): 389-396. https://doi.org/10.1080/21658005.2014.972043

LioRDOS V. (2014b). Membership trends and attitudes of a Greek hunting community. European Journal of Wildlife Research 60: 821-826. https://doi.org/10.1007/s10344-014-0830-3 
Logothetis G. (1998). The hunting Activity at the Evros River Delta. Ecologic, Economic and Social impact. Hellenic Hunting Confederation Report - Alexandroupolis Hunting Club [in Greek].

LOYN R.H. (1991). Assessing and managing the impact of duck hunting in Victoria - a new approach. Wildfowl 42: 155-161.

MAVRIDIS S. (2018). Greece's economic and social transformation 2008-2017. Social Sciences 7 (1), 9: 1-14. https://doi.org/10.3390/socsci7010009

Mazaris D.A., Mamakis Y., Kalpakis S., Poulopoulos Y. \& Matsinos Y. (2008). Evaluating potential threats to birds in Greece: an analysis of a 10-year data set from a rehabilitation center. Oryx 42: 408-414. https://doi.org/10.1017/S003060530700066X

MONDAIN-Monval J.Y. \& GIRARD O. (2000). Le canard colvert, la sarcelle d'hiver et autres canards de surface. Faune sauvage 251: 124-139.

Mondain-Monval J.Y., Defos Du Rau P., Mathon N., Olivier A. \& Desnouhes L. (2006). The monitoring of hunting bags and hunting effort in the Camargue, France. In: BOERE G.C., GALBRAITH C.A. \& STROUD D.A. (eds) Waterbirds around the World: 862-863. The Stationery Office, Edinburgh.

MooIJ J.H. (2005). Protection and use of waterbirds in the European Union. Beiträge zur Jagd und Wildforschung 30: 49-76.

NAGY S., FLINK S. \& LANGENDOEN T. (2014). Waterbird Trends 1988-2012. Results of Trend Analyses of Data from the International Waterbird Census in the African-Eurasian Flyway. Report from Wetlands International WI, Ede, Netherlands.

PAdDing P.I., GobeIl J.F. \& Wentworth C. (2006). Estimating waterfowl harvest in North America In: Boere G.C., GAlbraith C.A. \& Stroud D.A. (eds) Waterbirds around the World: 849-852. The Stationery Office, Edinburgh.

Portolou D., Bourdakis S., Vlachos C., KASTRitis T. \& DimaleXis T. (eds). (2009). Important Bird Areas of Greece. Priorities Sites for Conservation. Hellenic Ornithological Society, Athens. [In Greek].

SMith R.I., Blohm R.J., KELLY S.T., REYNOLDS R.E. \& CASWELl F.D. (1989). Review of data bases for managing duck harvests. Transactions of the North American Wildlife \& Natural Resources Conference 54: 537-544.

SOKOS K.C., BirTSAS P.K., CONELLY J.W. \& PAPASPYROPOUlOS K.G. (2013). Hunting of migratory birds: disturbance intolerant or harvest tolerant? Wildlife Biology 19: 113-125. https://doi.org/10.2981/12-032

Sorrenti M., Carnacina L., Radice D. \& Costato A. (2006). Duck harvest in the Po, Italy. In: Boere G.C., Galbraith C.A. \& Stroud D.A. (eds) Waterbirds around the World: 864-865. The Stationery Office, Edinburgh.

Stafford D.J., Pearse A.T., Hine C.S., Yetter A.P. \& Horath M.M. (2010). Factors associated with hunter success for ducks on state-owned land in Illinois, USA. Wildlife Biology 16: 113-122. https://doi.org/10.2981/09-071

Tsougrakis Y., Panagiotopoulou M. \& Makriyanni E. (2009). Public awareness campaign for the Lesser White-fronted Goose in Greece. In: Tolvanen P., OIEN I.J. \& RUOKOLAINEN K. (eds) Conservation of Lesser White-fronted Goose on the European Migration Route: 65-67. Final Report of the EU LIFE Nature project 2005-2009, WWF Finland Report 27 \& NOF Rapportserie Report No $1-2009$.

VAngeluwe D., Rosenfeld S.B., Volkov S.V., KAZAnTZidis S., Morozov V.V., ZAMYatin D.O. \& KIRTAEV G.V. (2018). Migration of Bewick's Swan (Cygnus bewickii): new data on tagging the migration routes, stopovers and wintering sites. Biology Bulletin 45: 90-101.

https://doi.org/10.1134/S1062359018070178 
Vougioukalou M., KaZANTZidis S. \& AarVAK T. (2017). Safeguarding the Lesser White-fronted Goose Fennoscandian Population at key staging and wintering Sites within the European Flyway. HOS/ Birdlife Greece, HAOD/Forest Research Institute, NOF/Birdlife Norway.

ZALIDIS C.G. \& MANTZAVELAS A.L. (1994). Inventory of Greek Wetlands as natural Resources (First approximation). Greek Biotope/Wetland Center (EKBY), Thessaloniki.

Manuscript received: 3 October 2019

Manuscript accepted: 28 July 2020

Published on: 13 August 2020

Branch editor: Stuart Halse 


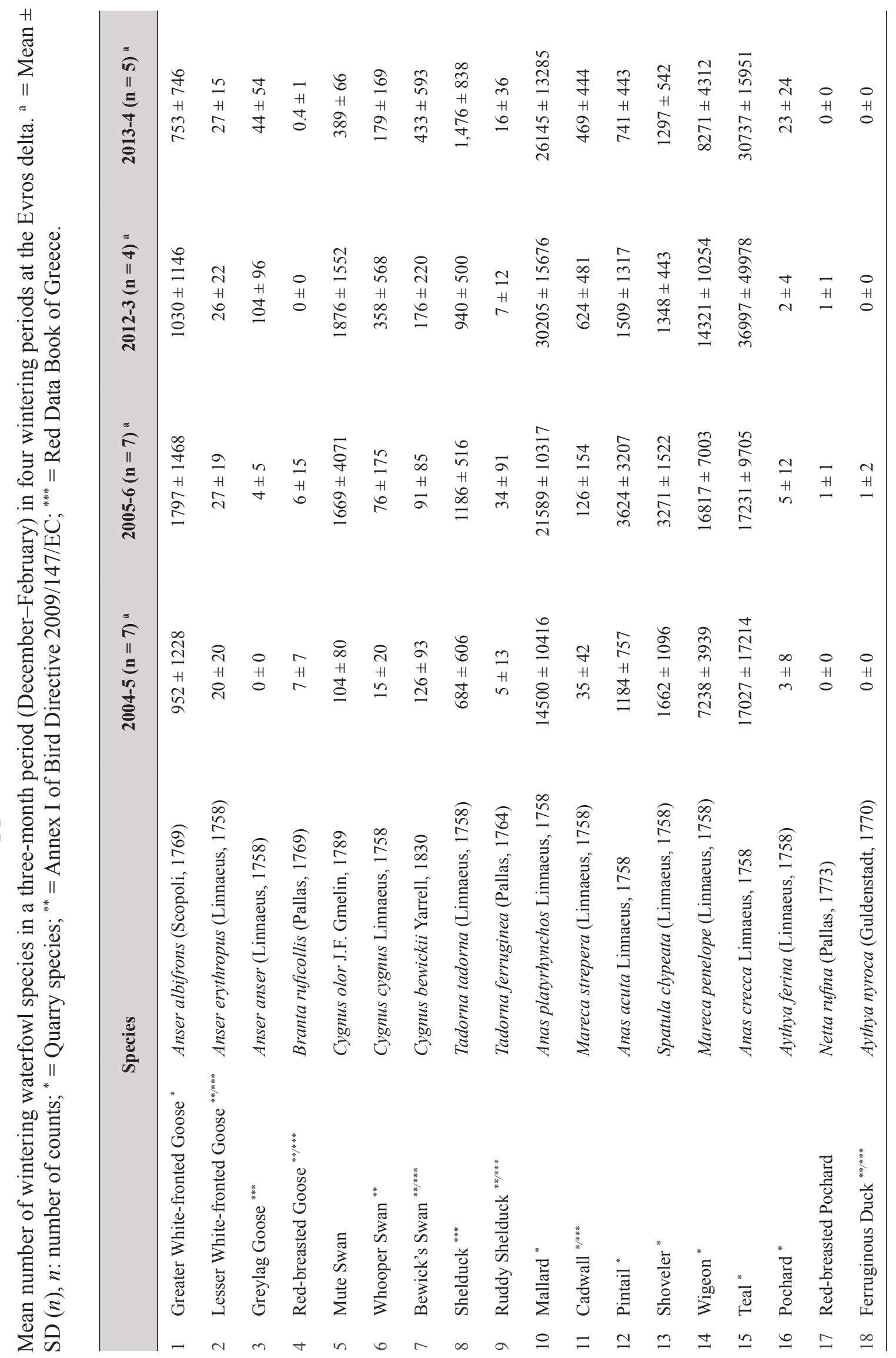




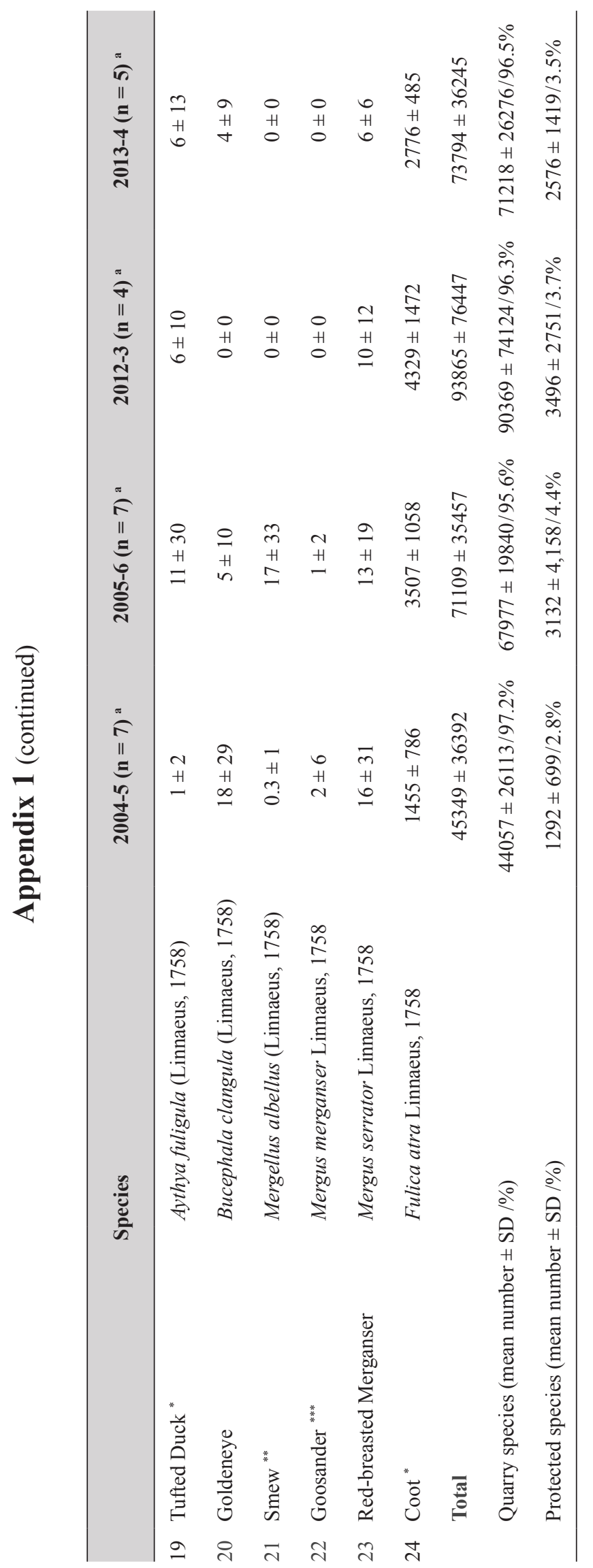

